\title{
Environmental life cycle cost assessment: Recycling of hard plastic waste collected at Danish recycling centres
}

\author{
Faraca, Giorgia; Martinez Sanchez, Veronica; Astrup, Thomas Fruergaard
}

Published in:

Resources, Conservation and Recycling

Link to article, DOI:

10.1016/j.resconrec.2019.01.014

Publication date:

2019

Document Version

Peer reviewed version

Link back to DTU Orbit

Citation (APA):

Faraca, G., Martinez Sanchez, V., \& Astrup, T. F. (2019). Environmental life cycle cost assessment: Recycling of hard plastic waste collected at Danish recycling centres. Resources, Conservation and Recycling, 143, 299-309. https://doi.org/10.1016/j.resconrec.2019.01.014

\section{General rights}

Copyright and moral rights for the publications made accessible in the public portal are retained by the authors and/or other copyright owners and it is a condition of accessing publications that users recognise and abide by the legal requirements associated with these rights.

- Users may download and print one copy of any publication from the public portal for the purpose of private study or research.

- You may not further distribute the material or use it for any profit-making activity or commercial gain

- You may freely distribute the URL identifying the publication in the public portal 
5 Environmental life cycle cost assessment: 6 recycling of hard plastic waste collected at 7 Danish recycling centres

10 Giorgia Faraca ${ }^{1 *}$, Veronica Martinez-Sanchez ${ }^{2}$, Thomas Astrup ${ }^{1}$

11

$12{ }^{1}$ Department of Environmental Engineering, Technical University of

13 Denmark, DK-2800 Kgs. Lyngby, Denmark

142 Fundació ENT, C/ Sant Joan 39, Vilanova i la Geltrú, 08800

15 Barcelona, Spain

18 *) Corresponding author: gfar@env.dtu.dk 


\section{Abstract}

29 Recycling of plastic waste is promoted by the European Union as an important 30 step toward a circular economy. Recovered plastic waste is a complex and 31 heterogeneous material, and the impurities and/or untargeted polymers 32 associated to plastic waste may affect the recycling process and potentially 33 decrease the intended benefits. An environmental and financial assessment was 34 conducted on one tonne of hard plastic waste collected at Danish recycling 35 centres. Three management scenarios were considered: two mechanical 36 recycling (a simpler and a more advanced configuration, namely sMR and 37 aMR) and a feedstock recycling (FR) scenario based on conversion through 38 pyrolysis. Scenario aMR provided the largest savings in the highest number of 39 impact categories (including global warming potential) and total costs; 40 scenarios sMR and FR provided smaller savings (or even burdens), depending 41 on the environmental impact category considered. A scenario analysis 42 evaluating the type of energy provision, location of recycling facilities and the 43 application of the recycled material confirmed the ranking of results with 44 respect to global warming potential and total costs. A global sensitivity assessment of model data inputs demonstrated that three to nine parameters were typically sufficient to achieve more than $90 \%$ of total variance of the results; critical parameters were mainly related to sorting efficiencies, technical yields and market substitution factors. The study demonstrates that if high quality of the recycled plastic is achieved, both environmental savings and financial revenues are possible.

51 Keywords: Circular economy; Life Cycle Assessment; Global Warming

52 Potential; Global Sensitivity Assessment; contamination; material recovery 53 facility

\section{Abbreviations}

55 eLCC: Environmental life cycle costing; EU: European Union; ET: terrestrial 56 eutrophication; FU: functional unit; GWP: global warming potential; HDPE: 57 high density polyethylene; HTc: human toxicity (cancer); HTnc: human 58 toxicity (non cancer); LCA: Life cycle assessment; LCC: Life cycle costing; 59 LDPE: low-density polyethylene; MRF: material recovery facility; MSWI: 60 municipal solid waste incinerator; NIR: near infra-red; PET: polyethylene 61 terephthalate; POFP: photochemical ozone formation; PP: polypropylene; PS: 62 polystyrene; PVC: polyvinyl chloride; SC: sensitivity coefficients; SR: 63 sensitivity ratios; TA: terrestrial acidification; TD: triangular distribution 


\section{Introduction}

65 Plastic represents a broad class of polymeric materials fulfilling a wide range

66 of purposes in today's society, depending on its mechanical and chemical

67 properties, e.g. for packaging, construction materials, transportation, 68 electronics, agriculture, etc. The European demand for plastic in 2016 was 57 69 million tonnes (EC, 2018), of which $70 \%$ was made of six main polymers: 70 polyethylene terephthalate (PET), high- and low-density polyethylene (HDPE 71 and LDPE), polyvinyl chloride (PVC), polypropylene (PP) and polystyrene 72 (PS). Plastic eventually becomes waste, which is estimated at about 25 million 73 tonnes (in 2015; Plastic Europe, 2016) and about 10-15\% of total municipal 74 solid waste in Europe (e.g. Giugliano et al., 2011; Rigamonti et al., 2013; 75 Miljøstyrelsen, 2014). About $85 \%$ of this plastic waste is made from the six 76 polymer types mentioned previously (Villanueva and Eder, 2014). In Denmark, 7733000 tonnes of plastic waste are generated every year (Miljøstyrelsen, 2017a).

78 To increase circular economy solutions and resource efficiency, the recycling 79 of these materials is important. However, little attention has been paid to 80 identifying the most appropriate recycling options from an environmental and 81 financial perspective.

82 The European Union (EU) promotes recycling as an important step toward a 83 circular economy (EEA, 2016; EPRS 2016), and in early 2018 a strategy was 84 released to address challenges related to plastic waste recycling (EC, 2018). In 85 2015, EU Member States recycled 30\% of plastic waste generated by 86 consumers, i.e. post-consumer plastic waste (Plastic Europe, 2016). In 87 Denmark, around 20\% of post-consumer plastic waste is recycled, while the 88 rest is incinerated (less than 5\% is landfilled; Plastic Europe, 2016); only hard 89 plastic waste (rigid products such as bottles and containers, pots, pipes, crates, 90 toys, etc.; see definition in Appendix B) is generally recycled in Denmark. This 91 relatively low recycling rate reflects a traditionally low coverage of separate 92 collection for plastic waste in many municipalities (Miljøstyrelsen, 2017b; 93 Sweco Danmark A/S, 2015) and the presence of a deposit-refund scheme for 94 plastic bottles, which until recently was not accounted in the national recycling 95 rates (DRS, 2015). In many parts of Denmark, recycling centres represent an 96 important collection method for plastic waste (Larsen et al., 2010). Recycling 97 centres are manned collection points where the waste is sorted into around 40 98 material fractions. This collection method is used widely across the UK, 99 Denmark, Norway and Sweden (Krook et al., 2010), with 44-50\% of source100 separated post-consumer plastic waste collected from Danish recycling centres 
101 in 2015 (Miljøstyrelsen, 2017b; Sweco Danmark, 2015). In the rest of Europe,

102 recycling centres account for 10-15\% of collected recyclables (Villanueva and

103 Eder, 2014). As the composition and quality of collected plastic waste is

104 affected by the collection system itself, specific attention has to be paid to

105 materials originating from these recycling centres. Today, such studies are

106 scarce in literature.

107 An assortment of plastic recycling options exists, differing in number, type and

108 sequence of processes. Recycling processes for plastic waste have been

109 classified by the scientific literature and legislation standards as a) primary (re-

110 extrusion), b) secondary (mechanical recycling), c) tertiary (feedstock or

111 chemical recycling) and d) quaternary (energy recovery) routes, according to

112 the technology used and the output produced by the process (e.g. ASTM

113 D5033; Brems et al., 2012; Ignatyev et al., 2014). While primary recycling

114 routes are applied to pre-consumer (industrial) plastic only, due to the high

115 level of homogeneity requested, traditionally secondary recycling routes have

116 been the main option for processing post-consumer plastic waste. Secondary

117 recycling involves sorting and reprocessing steps to produce single-polymer

118 pellets, granulates or flakes for use in new plastic products. Tertiary routes

119 represent technologies involving breaking down the polymer chains into

120 smaller molecules. Technologies like hydrolysis and pyrolysis produce liquids

121 that can be used in the production of new plastics, synthetic fibres, lubricants

122 and fuels, or other products used by the chemical industries (Ignatyev et al.,

123 2014; Yu et al., 2016). Finally, quaternary routes involve any type of energy

124 recovery. The European Waste Framework Directive (WFD) recognises as

125 recycling only those processes producing outputs that can be used as secondary

126 raw materials (EC, 2008). Mechanical recycling certainly falls into this

127 category, whereas the classification of tertiary technologies depends on the

128 final use of the product (Villanueva and Eder, 2014). Quaternary routes are not

129 defined as recycling by the WFD and will not be addressed in this study. Table

130 B.1 in the Appendix describes key differences between recycling routes.

131 Recycling is generally accepted as a sustainable waste management strategy;

132 however, plastic waste recycling is often more complicated than for other

133 material fractions (e.g. glass and metals; Alwaeli, 2009; Rigamonti et al.,

134 2015). Difficulties arise mainly from presence of impurities that may act as

135 technical, economic and/or market barriers to substitution of virgin plastic

136 (RDC Environment, 2003). Impurities in plastic waste may be grouped into

137 three classes: non-plastic components (foreign materials), non-targeted plastic

138 (different polymers than the one targeted for reprocessing, including multi- 
139 plastic products and polymer blends) and chemical impurities (bound to the 140 plastic matrix, such as pigments, additives, stabilizers, etc). In the EU, the 141 presence and concentration of impurities is regulated in plastic products (i.e. 142 "input" to the waste phase) and in the outputs from the reprocessing industry 143 (the recyclates; EN 153-42 to -48; ISRI, 2017). Business-to-business 144 specifications are also widely used (Villanueva and Eder, 2014). These 145 standards reflect that impurities may have various consequences on mechanical 146 recycling, from decreasing processing efficiencies, through lowering the 147 mechanical performance of recyclates, to inclusion of unwanted (and 148 potentially hazardous) chemicals in the product matrix. The purity of plastic 149 waste is the primary factor determining the quality and economic value of 150 recyclates (ISRI, 2017), and it is in turn dependent upon the type and number 151 of sorting and reprocessing steps. The presence of impurities influences 152 recycling costs not only in terms of investments in machinery required for 153 sorting, but also in terms of potential revenues from selling the recycled 154 materials: the lower the quality of the final product, the lower the revenues 155 (e.g. Rigamonti et al., 2015; Villanueva and Eder, 2014). On the contrary, 156 tertiary routes like pyrolysis can adapt to high levels of waste contamination 157 (Brems et al., 2012; Lofti, 2003), can replace multipurpose products with 158 material and energy application (Gear et al., 2018) and prevent the recycling 159 of chemical impurities along with the plastic material, thus becoming an 160 attractive choice (Yu et al., 2016).

161 The selection of the plastic waste recycling route usually depends upon factors 162 such as location, polymer type, product type, method of collection, presence of 163 impurities, desired quality of the product and raw material prices offered by 164 companies sorting or recycling the waste (Ragaert et al., 2017; Valentino, 165 2016; Yu et al., 2016). The export of recyclables is common in Europe, as the 166 plastic recycling industry is characterised by a large number of entities, each 167 performing a certain role in the recycling chain, linked by market agreements 168 which are very volatile and depend on "who-offers-more" as well as the price 169 of virgin materials (Villanueva and Eder, 2014). The main European importers 170 of plastic waste are Germany, the Netherlands, and Italy (EC, 2018). Although 171 an international market for recyclables may promote more recycling, 172 international exchange of recyclable materials may also reduce transparency 173 and traceability of waste materials, thereby making more difficult the 174 accounting of environmental impacts and total management costs.

175 The environmental consequences of plastic waste recycling and management 176 have been addressed through life cycle assessment (LCA) in numerous studies 
177 in the literature, e.g. Al-Salem et al. (2014), Benavides et al. (2017), Eriksson

178 and Finndevenn (2009), Ferreira et al. (2014), Gear et al. (2018), Rigamonti et

179 al. (2014), Shonfield (2008) and Valentino (2016). Two reviews (Bernardo et

180 al., 2016; Lazarevic et al., 2010) compared existing studies and concluded that

181 generally mechanical recycling is the environmentally preferred management

182 option. However, as the net environmental benefits provided by recycling

183 processes cannot stand alone as a basis for decision-making, an evaluation of

184 financial considerations is also required. This may be achieved through Life

185 Cycle Costing (LCC), which allows for consistent and integrated evaluation of

186 both environmental (LCA) and financial aspects (Martinez-Sanchez et al.,

187 2015; Swarr et al., 2011). Unfortunately, economic assessments focusing on

188 recycling routes for source-sorted plastic waste are scarce in the literature (Lea,

189 1996; WRAP, 2009). None of these studies involved LCA. Furthermore, none

190 of the studies in literature have addressed plastic waste collected at recycling

191 centres.

192 Existing environmental assessments of plastic waste recycling in the literature

193 have covered primarily plastic packaging collected at households, focusing

194 only on a few polymer types (e.g. Arena et al., 2003; Da Cruz et al., 2012;

195 Perugini et al., 2005), or have been included as a part of a broader waste system

196 evaluation (e.g. Massarutto et al., 2011; Sadhukhan et al., 2016). Most LCA

197 scenarios considered in these studies have addressed "macro-options" such as

198 recycling vs. incineration vs. landfilling; only a few cases have reported

199 detailed information about recycling processes (e.g. Shonfield, 2008). Existing

200 economic analyses of plastic recycling have focused mainly on collection

201 methods and approaches for increasing collection rates, as opposed to the

202 recycling processes themselves (Beigl et al., 2004; Hage and Söderholm, 2008;

203 Larsen et al., 2010; Massarutto et al., 2011). To improve plastic waste 204 recycling further, specific focus on the environmental and economic 205 performance of representative recycling options is needed while reflecting the 206 actual composition and quality of plastic waste collected at recycling centres.

207 The overall aim of this study is to provide an integrated environmental and 208 financial assessment of key recycling routes for hard plastic waste from Danish 209 recycling centres. The intention is to provide an improved basis for decision210 making in relation to plastic waste from recycling centres. This is achieved 211 through environmental life cycle costing (eLCC) focusing on the following 212 specific objectives: i) definition of arch-type recycling process configurations 213 relevant for a European context, to illustrate key differences in approaches, ii) 214 eLCC modelling of selected scenarios representing these arch-type recycling 
configurations, iii) ranking of scenarios and identification of critical process

216 parameters influencing the performance of each scenario, and iv) evaluation of

217 the influence of the quality of post-consumer plastic waste on the results.

\section{Materials and methods}

\subsection{Goal and scope definition}

220 In an eLCC a financial analysis is complemented by an LCA for the same 221 system. Therefore goal, scope, functional unit (FU) and system boundaries of 222 the LCA and LCC must be identical (Hunkeler et al., 2008). The FU adopted 223 in the modelling was the management of 1 tonne of post-consumer hard plastic 224 waste collected at recycling centres and with the following composition: 53\% 225 PP, 19\% PE, 2\% PET, 1\% PS, 10\% other polymers and 15\% impurities 226 (including PVC corresponding to 6\% of total PW) (data from Miljøstyrelsen, 227 2015, 2017b; Swaeco Danmark, 2015). Plastic films and PVC are collected 228 separately from hard plastic at Danish recycling centres; any presence of these 229 two plastic types was accounted for as misplacements (impurities) within the 230 recycled plastic. The geographical scope was Denmark; the temporal scope was $231 \quad 2017-2030$.

\section{2.1.1 Definition of scenarios}

233 This study addresses "typical" European solutions for the management of post234 consumer plastic waste (i.e. leaving aside process details, as detailed 235 evaluations have been provided in existing literature), therefore three arch-type 236 system configurations were selected among those suggested in the literature 237 (see Figure 1 and Appendix $\mathrm{C}$ for details): i) two mechanical recycling 238 scenarios (one simple configuration and one involving a more advanced 239 system) and ii) one feedstock recycling scenario (pyrolysis). The aim was not 240 to include an exhaustive list of possible scenarios but rather to evaluate main 241 types of recycling systems representing key differences in approach.

242 Scenario 1: simple mechanical recycling (sMR)

243 The plastic is sorted at a material recovery facility (MRF) comprising two near 244 infra-red (NIR) scanners. The targeted plastic outputs are PP and PE, while the 245 remaining part of the FU is incinerated. Other studies report HDPE and PET 246 as MRF-targeted output (e.g. Sadhukhan and Martinez-Hernandez, 2017); 247 however, in our case the PET fraction in plastic waste from recycling centres 248 is too low to be targeted in a simple MRF. Recovered PP and PE enter 249 individual reprocessing lines that include washing, grinding, ferrous and non- 
250 ferrous metal separation, floating and pelletizing into recycled pellets 251 substituting for virgin counterparts.

252 Scenario 2: advanced mechanical recycling (aMR)

253 The plastic is sorted at an MRF comprising a range of steps: manual sorting 254 (aiming at separating PVC and impurities from the main stream), shredding, 255 sieving, ferrous and non-ferrous metal separation and four NIR scanners. The 256 targeted outputs are PP, PE, PET and PS. PVC and metal impurities separated 257 out from the plastic flows are sent to further processing and recycling. Any 258 remaining materials are incinerated. The plastic reprocessing steps include 259 grinding, washing, drying and pelletizing into recycled pellets that substitute 260 for corresponding virgin materials.

261 Scenario 3: Feedstock recycling (FR)

262 The plastic undergoes a manual sorting step whereby PVC is separated from 263 the main stream (PVC must be $<2 \%$ of the input to avoid processing problems

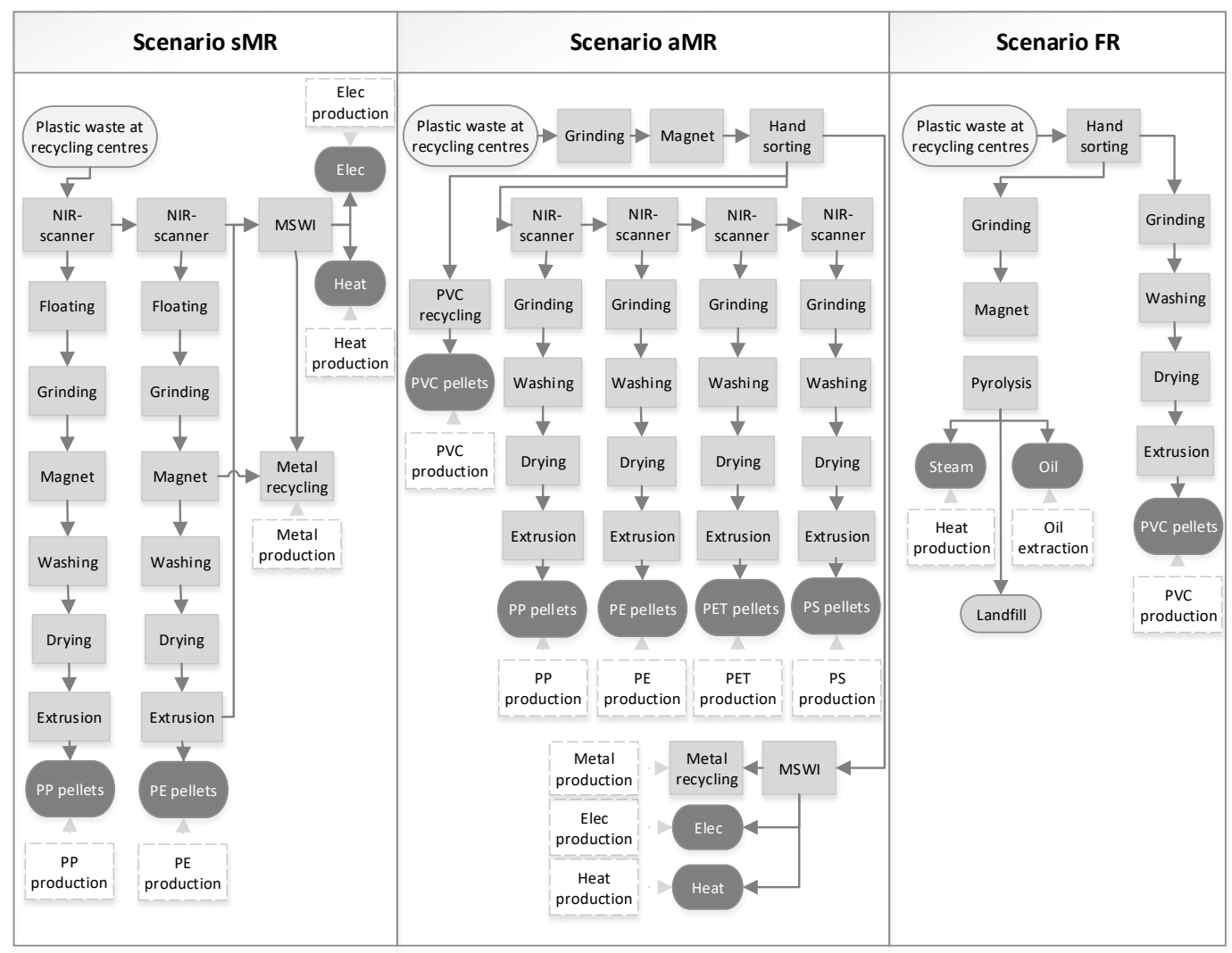

265 Figure 1. System boundaries for scenarios sMR (simple mechanical recycling), aMR 266 (advanced mechanical recycling) and FR (feedstock recycling). Elec = electricity; NIR= near 267 infra-red separator; MSWI = municipal solid waste incinerator. Light-grey boxes represent 268 processing steps; dark-grey ovals represent co-products; white-dashed boxes represent 269 avoided processes. 
271 (Al-Salem et al., 2014; Elli and Pagani, 2017)). After being shredded to the

272 right dimension (10 to $100 \mathrm{~mm}$ ) and separated from metals, the pre-treated 273 plastic waste is fed to a pyrolysis chamber. The waste is heated without oxygen 274 until it breaks down into oils and gases, leaving a residue (char) rich in carbon 275 and inorganic content from the original waste (Astrup and Bilitewski, 2010). 276 The yield of gas and liquids depends on the specific pyrolysis system and the 277 molecular composition of the plastic feedstock (Benavides et al., 2017), but 278 generally exceeds $70 \%$ by weight (Alston and Arnold, 2011). Although not 279 included herein, due to lack of data, some pyrolysis plants involve the use of 280 catalysts to improve process efficiency (Benavides et al., 2017; Elli and Pagani, 281 2017). As catalyst amounts are low compared to the treated plastic (about $0.7 \%$ 282 per weight) and can be regenerated many times (Benavides et al., 2017), this 283 omission is found reasonable. The oil is used as secondary raw material 284 displacing crude oil; the steam is utilised on-site to heat the pyrolysis chamber.

\section{$285 \quad 2.1 .2$ System boundaries}

286 The system focuses on the sorting and reprocessing parts of the plastic waste 287 recycling chain. Therefore, the system boundaries (Figure 1) start by unloading 288 the collected PW at the MRF and end at the point of substitution of secondary 289 materials or final management of any residual fractions. This excludes the 290 collection phase at the recycling centres and transport between recycling 291 centres and the MRF; these are identical for all scenarios and the exclusion has 292 no consequences for the comparison between scenarios. For the two scenarios 293 involving mechanical recycling (sMR and aMR), the model ends with the 294 substitution of virgin plastic pellets. Similarly, the pyrolysis scenario (FR) ends 295 by substituting crude oil based on the generated pyrolysis oil; further upgrading 296 of the pyrolysis oil was assumed similar to the substituted crude oil and not 297 included in the assessment.

\section{$298 \quad 2.2$ Assessment method}

299 The environmental and financial assessments followed a consequential 300 approach to support decision-making and reflect potential changes in the 301 management of plastic waste (Weidema et al., 2009; ISO14044, 2006). Co302 products relative to the functional unit were addressed by system expansion 303 and substitution (ISO 14040, 2006). The modelling was carried out with the 304 dedicated waste LCA model EASETECH developed by DTU Environment, 305 Technical University of Denmark (see Clavreul et al., 2014; Martinez-Sanchez 306 et al., 2015). 


\subsubsection{Environmental assessment}

308 The impact assessment followed the ILCD recommended method 2013 309 (Hauschild et al., 2013). Assessed impact categories included: global warming 310 potential (GWP100), human toxicity (cancer, HTc, and non-cancer, HTnc), 311 photochemical ozone formation (POFP), terrestrial acidification (TA), and 312 terrestrial eutrophication (ET). No normalisation or weighting was applied. In 313 the interpretation of results emphasis was placed on GWP, as this impact 314 category is based on widely accepted concepts and well-established 315 characterisation factors. Detailed results for all impact categories can be found 316 in Appendix $\mathrm{H}$.

\section{$317 \quad 2.2 .2$ Financial assessment}

318 The financial part of the eLCC addressed monetary flows associated with the 319 FU (i.e., how costs and revenues were affected by the FU as represented by the 320 individual scenarios). As the assessment was not intended to evaluate monetary 321 flows between concrete actors within the recycling chain, it was assumed that 322 all necessary services were provided by a single actor. The assessment included 323 budget costs and transfers but did not include externalities, according to 324 Hunkeler et al. (2008). Budget costs included capital costs (expenditure for 325 machinery, maintenance of equipment) and operational costs (manpower 326 wages, energy and material consumption). Transfers included taxes, subsidies 327 and fees applied to the recycling chain (mainly energy taxes, emission taxes, 328 salary taxes and social security taxes). Costs were obtained for 2017 as a 329 reference year. Please refer to Martinez-Sanchez et al. (2015) for further 330 methodological details related to the LCC of waste management systems.

\subsection{Uncertainty, sensitivity and scenario analysis}

332 A number of approaches is available in the literature for sensitivity and 333 uncertainty analysis (e.g. Clavreul et al., 2012; Groen et al., 2014; Laurent et 334 al., 2014). In this study, uncertainty on the foreground system (including waste 335 management activities) was addressed through global sensitivity assessment, 336 which is not commonly used within waste management LCAs and was 337 demonstrated to allow identifying important aspects governing LCA results 338 (Bisinella et al., 2017); uncertainty on the background system (interacting with 339 the foreground system by supplying energy and material inputs, including 340 avoided energy and virgin material production) was addressed by scenario 341 analysis. 


\subsubsection{Uncertainty analysis}

343 In order to define the uncertainty associated with the input values, inventory 344 data were inserted as ranges by defining all parameters describing the 345 foreground system as probability distributions (Bisinella et al., 2017). Due to 346 the diversity of the information available in the scientific literature, triangular 347 distributions of the type TD (min,max,mode) were assumed. When the mode 348 (the value appearing most often) could not be calculated, the median (the value 349 separating the higher half from the lower half of the data sample) was used 350 instead. The mode/median represented the baseline value used in the model, 351 while the entire distribution was used for uncertainty propagation, where 352 uncertainties associated with each input parameter were propagated to 353 calculate the uncertainty associated with the results. Based on Monte Carlo 354 analysis, input values were sampled from the probability distribution 355 associated with each parameter, and the results were calculated following the 356 approach of Bisinella et al. (2016).

\section{$357 \quad 2.3 .2$ Sensitivity analysis}

358 Sensitivity analysis identifies how results vary as a consequence of a change 359 in input values (Bisinella et al., 2016). It comprises a perturbation analysis, 360 which is performed by increasing each parameter by $10 \%$ of its value in a "one361 at-a-time" manner while keeping all other parameters fixed at their baseline 362 values. Results from the perturbation analysis enable the calculation of 363 sensitivity coefficients (SCs) and sensitivity ratios (SRs) associated with each 364 parameter (Equations F.1 and F.2 in Appendix F). While the calculation of SRs 365 provides information about the sensitivity of the model to each parameter, SCs 366 are used to calculate and rank the contribution of individual parameters to total 367 variance, thereby evaluating the importance of individual parameters relative 368 to the results and on this basis identifying the most critical parameters.

\section{2.3.3 Scenario analysis}

370 A range of assumptions regarding the background system were necessary in 371 order to complete the modelling: i) the type of energy provision, ii) the 372 geographic location of facilities, and iii) the materials substituted by the 373 recycled products. The robustness of the model to these assumptions was tested 374 by scenario analysis. In the baseline situation, marginal electricity production 375 was assumed to consist of wind and biomass and marginal heat production to 376 represent natural gas boilers. In the scenario analysis, one "fossil" alternative 377 was evaluated. Two alternative geographic locations for the facilities were 378 evaluated in addition to the baseline situation (Denmark): Germany (scenarios 
"sMR-DE", "aMR-DE", and "FR-DE") and Italy (scenarios "sMR-IT", "aMR380 IT", and "FR-IT"), as the two major importers of plastic waste in Europe. 381 Regarding the selection of substituted virgin materials, an alternative situation 382 for the sMR scenario was evaluated with the assumption that recycled plastic 383 pellets substituted wood plastic composites (WPC) instead of virgin plastic 384 pellets (scenario "sMR-WPC"). This alternative reflected a situation in which 385 the purity of the separated plastic entering the reprocessing step was too low 386 to ensure substitution of virgin polymers into pure plastic applications 387 (Villanueva and Eder, 2014). Appendix G presents an overview of the 388 considered parameters and their variations.

\subsection{Life cycle inventory}

390 Data applicable to Denmark were used when available; otherwise European 391 data were applied.

\section{$392 \quad 2.4 .1$ Operational data}

393 A clear relationship between operational parameters (sorting efficiencies, 394 technical yields, substitution factors, energy and material consumption) and $395 \mathrm{MRF} /$ reprocessing facility configurations (number and types of individual unit 396 processes) could not be found in the available literature. Therefore, data ranges 397 were identified for relevant operational parameters and divided into two 398 subintervals: a lower interval [min; mode] representing the simple MRF and 399 an upper interval [mode; max] for the advanced MRF. As such, two 400 subintervals representing individual distributions were defined for each 401 parameter. The means for each of these subintervals (a "lower" mean and an 402 "upper" mean) were used as baseline values in the sMR and aMR scenarios, 403 respectively.

404 Table 1 lists the baseline values for sorting efficiencies, technical yields and 405 market substitution factors of targeted polymers adopted in the sMR and aMR 406 scenarios, as well as conversion efficiencies adopted in the FR scenario. The 407 marginal electricity provision for Denmark was calculated according to Muñoz 408 et al. (2015) with data from EC (2016) and consisted of 61\% wind energy and $40939 \%$ energy from biomass. All residual fractions from the MRF (including 410 unrecovered plastic and impurities) were assumed incinerated at MSWI with 411 electricity and heat recovery (fly and bottom ashes were assumed landfilled, 412 while iron scrap recovered from bottom ashes was assumed recycled). In the 413 case of the feedstock recycling (FR) scenario, pyrolysis char was assumed 414 landfilled. A large number of publications was used as data sources: see 415 Appendix D and $\mathrm{E}$ for a full list of included inventory data and processes. 
416 Table 1. Baseline values for sorting efficiencies, technical yields and market substitution 417 factors adopted in scenarios simple mechanical recycling (sMR), advanced mechanical 418 recycling (aMR) and feedstock recycling (FR). Additional information is provided in Table 419 D.1.

\begin{tabular}{llll}
\hline Polymer & $\begin{array}{l}\text { Sorting } \\
\text { efficiency }\end{array}$ & $\begin{array}{l}\text { Technical } \\
\text { yield }\end{array}$ & $\begin{array}{l}\text { Market substitution } \\
\text { factor }\end{array}$ \\
\hline Scenario sMR & & & \\
\hline PP & $55 \%$ & $69 \%$ & 0.48 \\
PE & $62 \%$ & $76 \%$ & 0.66 \\
\hline Total recovery & & $36 \%$ & \\
\hline Scenario aMR & & & \\
\hline PP & $81 \%$ & $86 \%$ & 0.83 \\
PE & $84 \%$ & $91 \%$ & 0.91 \\
PET & $65 \%$ & $88 \%$ & 0.95 \\
PS & $65 \%$ & $77 \%$ & 0.66 \\
\hline Total recovery & & $67 \%$ & \\
\hline Scenario FR & & & \\
\hline Crude oil & - & $80 \%$ & 0.90 \\
Steam & - & $12 \%$ & 1.00 \\
\hline
\end{tabular}

\section{$421 \quad 2.4 .2$ Cost data}

422 Cost data were retrieved from scientific literature and reports, converted to $423 € /$ tonne of treated material as described in Martinez-Sanchez et al. (2015; 424 2016), and inserted as triangular distributions when possible. All budget costs 425 were annualised and related to the annual capacity of the relevant facility, 426 assuming 15000 tonnes/year (Clean, 2017). The cost of machinery was 427 normalised by the annual usage rate of the machinery (Martinez-Sanchez et al., 428 2015). Discounting of future costs and benefits were not included, according 429 to Larsen et al. (2010). The price of recyclable plastic was obtained by 430 multiplying the market substitution factor with the price of the virgin 431 counterparts. Transfers included energy taxes, emission taxes, salary taxes and 432 social security taxes. Taxes on energy consumption excluded refundable taxes, 433 levies and VAT that generally can be recovered by non-household users 434 (Eurostat, 2017a; 2017b). Environmental taxes on energy included energy 435 taxes, $\mathrm{CO} 2$ taxes, NOx taxes but not Public Service Obligation taxes as these 436 are expected to be phased out within 2022 (IEA, 2017). VAT on capital goods 437 was not included as this is typically recovered by business entities. Corporate 438 income taxes were likewise excluded as most waste management facilities in 439 Denmark are publicly owned and not allowed to generate profits. As costs 
440 related to collection and transport prior to the MRF were beyond the

441 assessment scope, these costs were not included (see Section 3.2). Detailed

442 inventory cost data can be found in Table D.7 in Appendix D.2.

$443 \quad 3$ 3. Results and discussion

\section{$444 \quad 3.1$ Environmental assessment}

445 The characterised impacts from the three scenarios are shown in Figure 2 for 446 selected impact categories (results for additional categories are provided in 447 Table H.1); the error bars represent variability in impact scores associated with 448 uncertainty in the input data. Considering data uncertainties, scenario aMR 449 provided significantly lower net impacts in all impact categories. While 450 scenarios sMR and FR generally had higher impacts than scenario aMR, 451 scenario sMR had significantly lower impacts than FR in four out of six impact 452 categories. Across all impact categories and accounting data uncertainties, the 453 scenario rank order was: 1) aMR, 2) sMR and 3) FR. While the error bars in 454 Figure 2 indicate a wide range of potential impact scores for the individual 455 scenarios, differences between individual scenarios for most of the impact 456 categories were significant (except in the case of HTnc). This indicates that the 457 conclusions regarding environmental impacts are relatively robust in view of 458 known parameter uncertainties.

459 For scenario aMR, net savings (excluding uncertainty) in HTc and TA were $460239 \%$ and $203 \%$ larger, respectively, compared with scenario sMR, and $74 \%$ 461 and $326 \%$ larger compared with scenario FR. Consistent savings were observed 462 for the impact categories POFP, GWP and ET, where the savings from scenario 463 aMR were always at least $159 \%$ larger than scenarios sMR and FR. The process 464 that contributed the most in the majority of impact categories was material 465 substitution for scenarios sMR and aMR and the pyrolysis process itself in 466 scenario FR. The difference between scenarios aMR and sMR (typically 467 ranking second) was due to lower substitution of virgin plastic, because of 468 lower recoveries and lower substitution factors associated with a lower quality 469 of the recovered plastic.

470 In terms of GWP, the results showed that only scenario aMR provided savings 471 (-717 kg CO2eq/FU), whereas scenarios FR and sMR resulted in a net burden 472 to the environment (374 and $940 \mathrm{~kg} \mathrm{CO} 2 \mathrm{eq} / \mathrm{FU}$ respectively). This ranking of 473 scenarios is in accordance with a UK study (Al-Saleem et al., 2014) demon- 

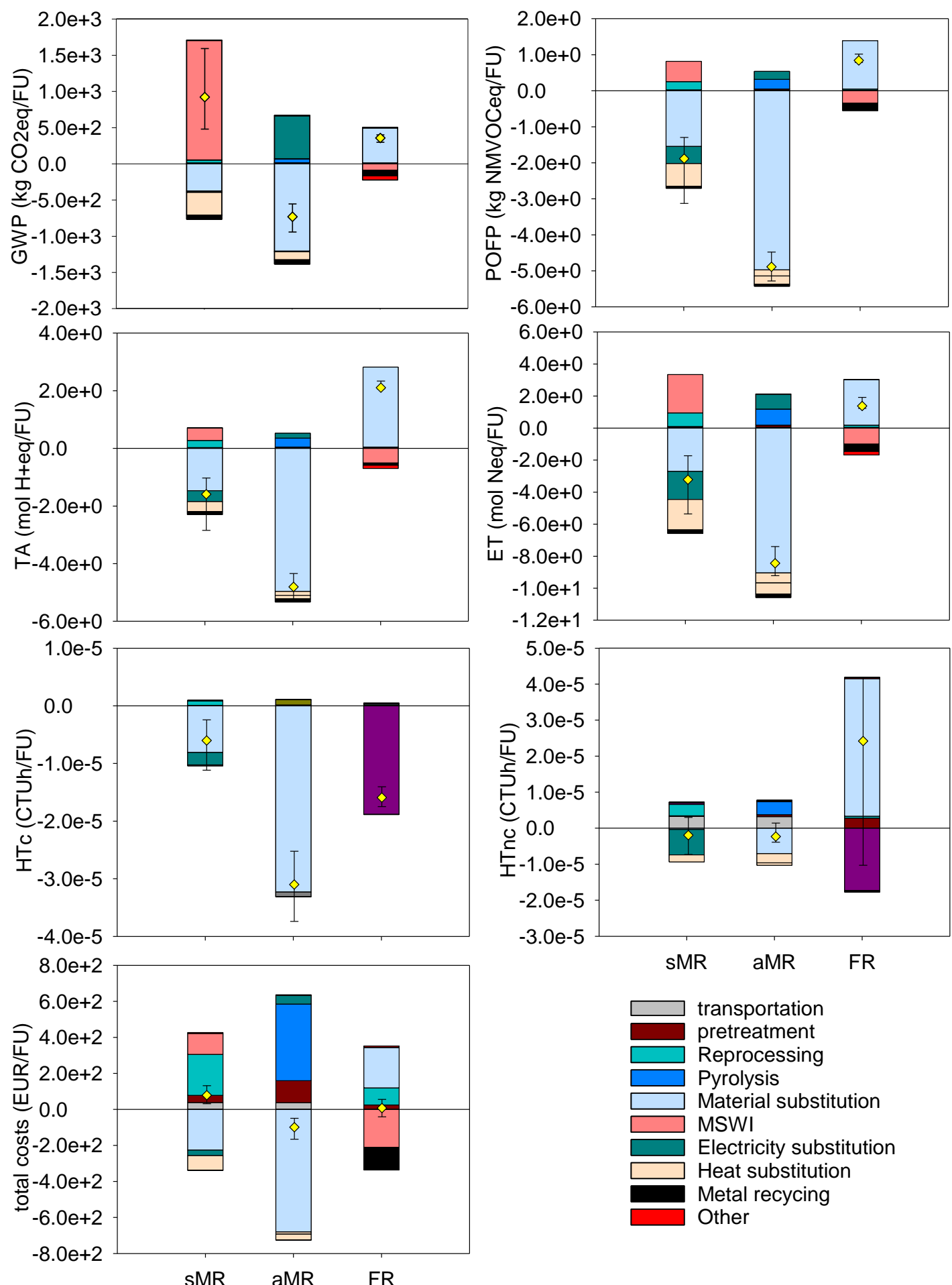

SMR aMR FR

475 Figure 2. Characterised results for scenarios simple mechanical recycling (sMR), advanced 476 mechanical recycling (aMR) and feedstock recycling (FR). "Other" in the legend includes 477 landfill and building of facilities. GWP: global warming potential; POFP: photochemical 478 ozone formation; TA: terrestrial acidification; ET: terrestrial eutrophication; HTc: human 479 toxicity, cancer effects; HTnc: human toxicity, non-cancer effects; MSWI: municipal solid 480 waste incinerator. Yellow diamonds represent net results; error bars represent the min and max results from the Monte Carlo analysis. See also Table H.1. 
strating that if the recycling chain (MRF + reprocessing) had a substitution

484 factor below 0.5, the pyrolysis technology would be environmentally 485 preferable. Rigamonti et al. (2014) obtained results in the same order of 486 magnitude for two mechanical recycling scenarios, while Shonfield (2008) 487 demonstrated that mechanical recycling of PP, PE, PET and PVC would save 488 around 500-700 kg CO2eq/tonne of plastic waste. Shonfield (2008) and Al489 Saleem et al. (2014) found a net load of 30-100 kg CO2eq/tonne plastic for a 490 pyrolysis scenario, considering the replacement of paraffin and naphta, while 491 Gear et al. (2018) provided results of 1-62 kg CO2/tonne plastic for a thermal 492 cracking option, depending on the replaced product.

493 Avoided virgin material production was the largest contributor to GWP savings 494 in scenario aMR (59\% of total impacts), while in scenarios sMR and FR this 495 accounted only for $15 \%$ and $11 \%$ of total impacts, respectively. Indeed, the 496 simpler configuration of the MRF in scenario sMR increased the presence of 497 untargeted polymers in the mixture to be recycled (the PP-stream and the PE498 stream included $10 \%$ and $25 \%$ of untargeted polymers that were incorrectly 499 sorted). When this happens, the recycler reprocesses the (impure) mixture at 500 the highest melting point of the polymers, causing the degradation of 501 components with lower melting points and the formation of burnout solids 502 (Ragaert et al., 2017): the market substitution factor in the modelling lowered 503 to take into account that these elements are undesirable in recycled materials, 504 as they interrupt the structure of final products and reduce mechanical 505 properties.

506 The largest contributor in scenario sMR was incineration which constituted $50767 \%$ of the environmental impacts. This was an indirect effect of the low 508 sorting efficiencies at the MRF (mainly due to the presence of a single 509 technology handling a very heterogeneous mix) and of the low reprocessing 510 yields (due to softening, surface contamination and biodegradation processes), 511 causing $641 \mathrm{~kg}$ of the $\mathrm{FU}$ to be sent to energy recovery. As the baseline 512 situation mainly included natural gas for heat production, $\mathrm{CO} 2$ emissions from 513 incineration (14\% of total GWP impacts) were not outbalanced by avoided 514 emissions from substituted energy production. Similar results have been 515 documented by other studies (e.g. Alston and Arnold, 2011; Rigamonti et al., 516 2014). For the same reason, $\mathrm{CO} 2$-eq emissions from the pyrolysis process 517 represent an important contribution ( $71 \%$ of total impacts). From a climate 518 impact perspective pyrolysis may therefore be similar to incineration 519 processes; this supports the classification as tertiary recycling only when the 
520 final product is used in material applications (new plastic, lubricants, etc.;

521 Villanueva and Eder, 2014).

$522 \quad 3.2$ Financial assessment

523 Scenario aMR was the only scenario providing net financial savings (-90

$524 € / F U)$. Scenarios FR and sMR ranked second and third, representing net costs 525 of $16 € / \mathrm{FU}$ and $87 € / \mathrm{FU}$ respectively (Figure 2 ).

526 Avoided virgin material production was the largest contributor to the results 527 (29\%, 50\% and 31\% in scenarios sMR, aMR and FR respectively) and 528 determined the net savings in scenario aMR: even if budget costs of aMR were 529 larger compared to scenarios sMR and FR ( $+182 \%$ and $+202 \%$ respectively), 530 they were off-set by larger revenues provided by selling recycled pellets 531 ( $+301 \%$ and $+323 \%$ respectively). These revenues were larger in scenario aMR 532 than in sMR not only because a larger quantity of plastic waste was processed 533 into recycled pellets (671 kg in scenario aMR vs $359 \mathrm{~kg}$ in scenario sMR), but 534 also because better material quality was obtained in scenario aMR than in sMR, 535 resulting in higher homogeneity at the polymer level, which was reflected by 536 higher prices. On the other hand, scenario sMR allowed larger revenues from 537 electricity and heat production from energy recovery $(+256 \%)$ than scenario 538 aMR, albeit such revenues were outbalanced by incineration and landfilling 539 costs from handling residues. The results demonstrated that insufficient sorting 540 in scenario sMR may lead to a recovered plastic mixture for which recycling 541 is not economically feasible (see also Section 3.3), as also suggested by 542 Villanueva and Eder (2014). Ragaert et al. (2017) also reported that insufficient 543 sorting can increase the total costs of recycled resins. When the quality of 544 recycled pellets is not high enough to compete in the market, possible solutions 545 include filler (e.g. talc) addition, compatibilisation, or virgin resins addition 546 (Ragaert et al., 2017; Sommerhuber et al., 2016; Vazquez and Barbosa, 2016), 547 which may increase costs further. Revenues from scenario FR came from 548 substituting crude oil and heat (31\% and $18 \%$ of total financial impacts, 549 respectively). However, the pre-treatment and processing of plastic waste 550 represented $14 \%$ and $33 \%$ of financial impacts respectively, leading to net 551 costs for the FR scenario. Other studies have reached similar conclusions and 552 reported that plastic waste pyrolysis is cost-effective only in the case of large 553 facility capacities (e.g. Axion Consulting, 2014; Yu et al., 2016).

554 Overall, the budget costs represented larger contributions than transfers (93\%, $55595 \%$, and $92 \%$ of absolute results in scenarios sMR, aMR and FR respectively). 556 Taxes on labour costs represented the main part of transfers; environmental 
557 taxes on energy consumption were almost negligible overall. Uncertainty in all

558 input data made results vary between 40 and 141 EUR/FU, between -158 and

$559-41 \mathrm{EUR} / \mathrm{FU}$, and between -33 and $64 \mathrm{EUR} / \mathrm{FU}$ for scenarios sMR, aMR and

560 FR respectively. While the observed variability in financial results represents

561 the quality of input data, it also illustrates the importance of systematically

562 including financial costs as part of an integrated assessment of recycling

563 solutions - in view of the potential political sensitivity of decision-making.

564 As collection is not included in the assessment, total costs were smaller than 565 identified by other studies (RDC Environment, 2003; Massarutto et al., 2011).

566 However, collection and transport have been shown previously to have minor

567 financial importance in the case of recycling centres (Larsen et al., 2010).

568 Overgaard et al. (2018) documented the price for reprocessing Danish hard

569 plastic waste to pellets (details unknown) at 80 EUR/tonne plastic waste, which

570 is very similar to our result for scenario sMR. The obtained results were

571 compared with the "management fee" that Danish waste collectors have to pay

572 for treatment of plastic waste. Based on a range of Danish waste collectors,

573 typical fees are estimated to be in the range of $0-200 € /$ tonne plastic waste.

574 While this range includes the results found for scenarios sMR and FR (although

575 pyrolysis plants are not common in Europe), the large variability in prices also

576 illustrates the volatility of the recycled plastic market. As scenario aMR

577 indicates net savings, and considering the substantial variability in MRF

578 performance across Europe, current Danish management fees suggest that

579 considerable improvements should be possible. This also indicates that by

580 moving toward higher quality in terms of output and recycling, the

581 management fees could be lowered or turned negative, i.e. representing a

582 revenue for municipalities collecting plastic waste, as it is now the case for 583 metals.

\section{$584 \quad 3.3$ Sensitivity and scenario analysis}

585 3.3.1 Importance of process parameters

586 The contribution of individual parameters to the overall variance of the results 587 is illustrated in Figure 3, including the information about the three most critical 588 parameters for each scenario. Overall, three to nine parameters were sufficient 589 to achieve more than $90 \%$ of the total variance in the environmental and 590 financial results, although for some impact categories and scenarios only three 591 parameters were sufficient (e.g. GWP and ET). Scenarios sMR and FR 592 appeared to be affected by fewer parameters than aMR. This difference 593 depended partly on the scenario modelling itself, but also on the complexity of 

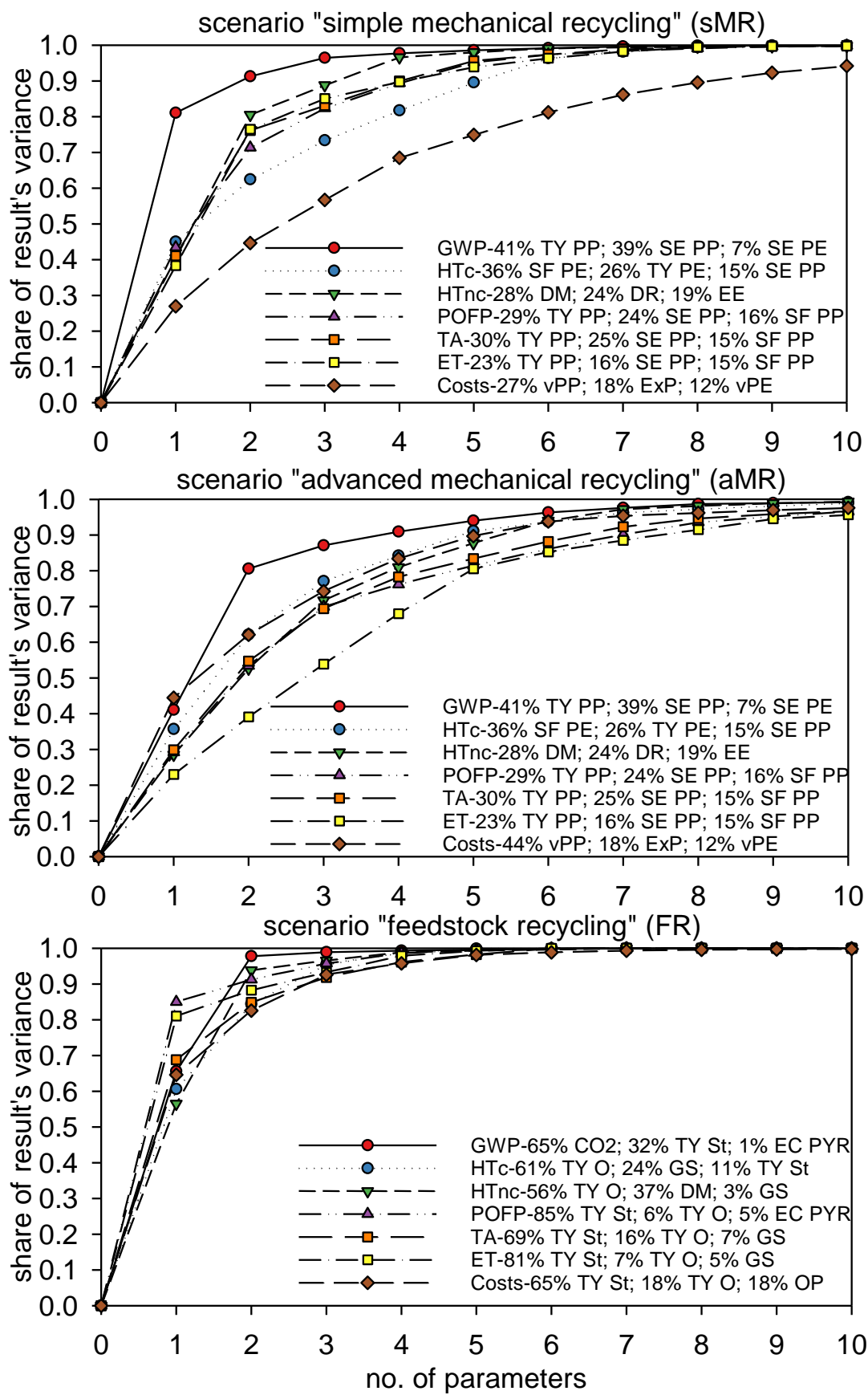

Figure 3. Contribution of individual parameters to overall variance of environmental and

596 financial results (top to bottom: scenarios sMR, aMR and FR). Values in the legend represent 597 the three most important parameters per impact category and the share of variance covered 598 by the corresponding parameter type. GWP: global warming potential; POFP: pho tochemical 599 ozone formation; TA: terrestrial acidification; ET: terrestrial eutrophication; HTc: human 600 toxicity, cancer effects; HTnc: human toxicity, non-cancer effects; TY: technical yield; SE: 601 sorting efficiency; SF: substitution factor; PP: polypropylene; PE: polyethylene; DM: 602 distance to MRF; DR: distance to recycling; EE: electricity efficiency at MSWI; vPP: virgin 603 PP price; ExP: price of extruder; vPE: virgin PE price; CO2: carbon dioxide emissions at 604 pyrolysis plant; St: steam; EC PYR: energy consumption at pyrolysis plant; O: oil; GS: gas 605 share in energy consumption at pyrolysis plant; OP: oil price. 
607 the technologies within the scenarios. The relatively few parameters 608 representing most of the total variance indicate that the best possible quality of 609 these data should be ensured, and that research efforts improving related 610 technology aspects are important. In this study, these parameters relied on data 611 from a review of 9-17 studies (see Tables D.1 and D.2). Data in the legend 612 refer to the first three data points in Figure 3 for a specific impact category and 613 scenario (see also Appendix I for additional results): for most impact categories 614 the more contributing parameters were related to sorting efficiency, technical 615 yield and market substitution factor.

616 As the market substitution factor may be challenging to estimate (see also 617 Vadenbo et al., 2017), Figure 4 shows the effect on GWP and total costs when 618 this parameter varies between 0 and 1 . The value for the market substitution 619 factor could determine whether the final results were positive or negative, most 620 prominently for the financial assessment and for scenario aMR (steeper 621 relationships). This clearly illustrates that the financial viability of recycling 622 depends on the market acceptance of the recycled pellets, as all scenarios 623 achieved net financial revenues in case of market substitution factors above 624 0.6-0.7. Market aspects such as image, risk of failure, poor characteristics 625 (odours, touch, appearance), difficulty in guaranteeing capacity and demand, 626 legislative barriers may significantly influence the acceptance of recycled 627 pellets (RDC Environment, 2003). While some of these challenges may be 628 addressed (poor image can be reversed and legislation may change), others may 629 constrain the recycled plastic market. This demonstrates that both 630 environmental and financial assessments should include the market 631 substitution factor as a parameter distribution rather than a single value.

632 It is important to realise that linearity between selling prices and quality of 633 recyclates is often assumed (as in this study, see Section 2.4.2). However, the 634 linearity between the two variables may not apply or may be "interrupted" at 635 some point, so that recycled pellets are sold with no revenues when the quality 636 decreases below a certain threshold, as in the case of municipal subsidies for 637 collection of recyclables that fall to zero in the case of large contamination of 638 the collectables (Rigamonti et al., 2015). If this is the case also for raw material 639 substitution, the economic expenditure required for scenario sMR could be 640 even higher. However, as LCC and LCA must share the same methodological 641 approach, and as no evidence could be found that such a relation exists for 642 Danish plastic waste, an identical substitution factor was applied to both parts 643 of the assessment. 


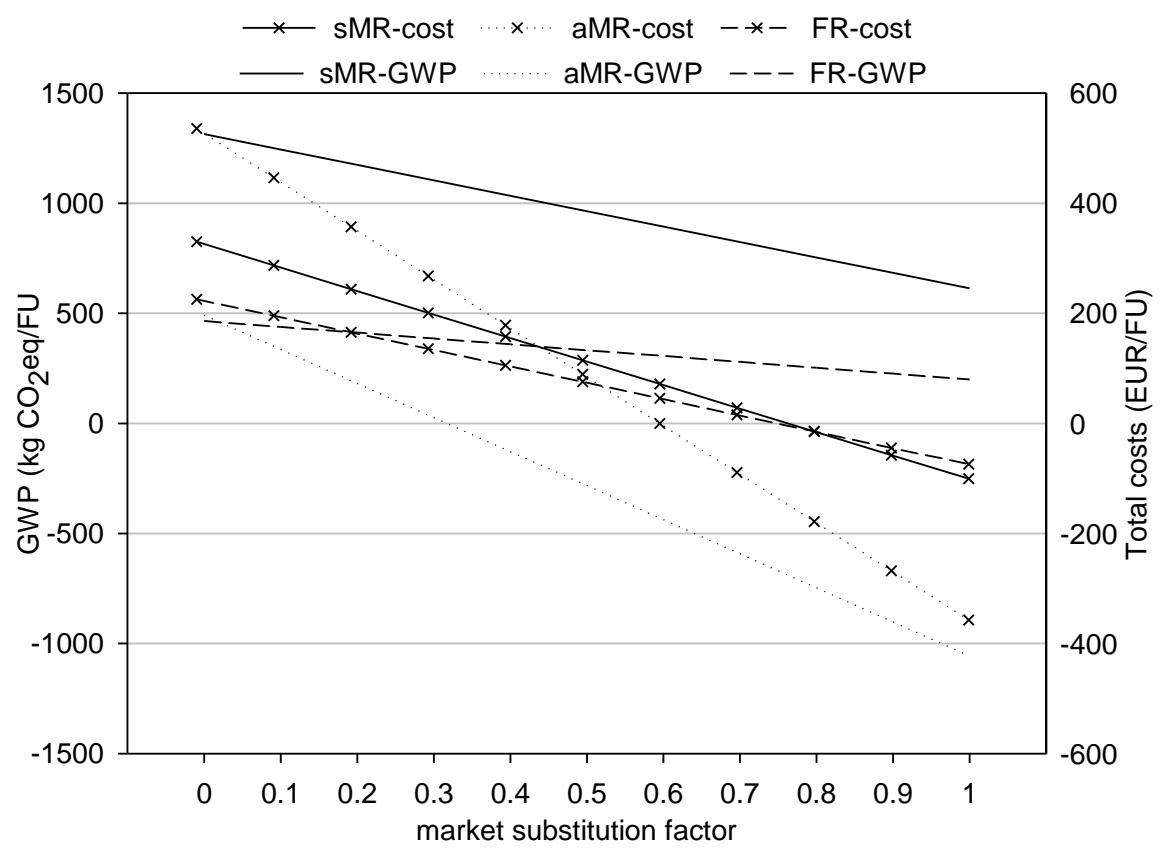

645 Figure 4. Behaviour of Global Warming Potential (solid lines; left-hand axis) and total costs 646 (dotted lines; right-hand axis) with decreasing degree of virgin plastic substitution.

647 As Figure 3 illustrates, financial results depended largely on the price of the 648 substituted virgin plastic. In this study a price of $1200 € /$ tonne was chosen as 649 a baseline, but it is important to remember that this value is closely linked to 650 oil prices which are extremely volatile. Decreasing oil prices will decrease the 651 price of virgin resins, and prices of recycled pellets would have to decrease 652 accordingly in order to be competitive; however, the cost of recycling would 653 remain constant. Changes in financial results when decreasing the price of 654 virgin resins to $1000 € / \mathrm{t}$ are substantial: $+63 \%$ in scenario sMR (109 EUR/FU) 655 and $+47 \%$ in scenario aMR (-65 EUR/FU).

\section{3.3.2 Importance of boundary conditions and background system}

657 Results from scenario analyses are provided in Figure 5 for GWP and financial 658 costs. The ranking of scenarios did not change when the energy provision 659 changed to fossil sources: scenarios FR and aMR were affected only slightly 660 by this choice ( $-15 \%$ and $+8 \%$ of emissions respectively). In this situation, the 661 use of thermal energy in the pyrolysis process (natural gas) became important, 662 and the larger savings in scenario aMR provided by energy substitution from 663 incineration were outbalanced by larger emissions from energy consumption 664 for sorting and processing plastic waste. Emissions in scenario sMR were 84\% 665 smaller than in a renewable energy system, due to the large savings from 666 recovery of energy replacing fossil fuels. In this situation, increased attention 667 must be given to the choice of electricity and heat efficiencies, as electricity 
668 efficiency was one of the main parameters in the baseline modelling (see Figure 669 3), and changing to a fossil-based electricity mix will increase the importance 670 of this parameter. In Europe, electricity and heat recovery at waste incinerators 671 typically range between 6-28\% for electricity and 6-74\% for heat (Alston and 672 Arnold, 2011; Eriksson and Finndeven, 2009; Turconi et al., 2011).

673 The scenario analysis on the location of the recycling process demonstrated 674 that exporting plastic waste resulted in higher GHG impacts and total costs. 675 The increase in GWP can be explained by three factors: transporting plastic 676 waste for longer distances, non-renewable energy in the country-specific 677 electricity mix, and smaller credits obtained from the substitution of energy 678 due to lower energy recovery efficiencies. The main financial contributor was 679 transportation cost which increased from 5\%, 3\% and 3\% in scenarios sMR, 680 aMR and FR to $26 \%, 17 \%$ and $28 \%$ in scenarios sMR-IT, aMR-IT and FR-IT 681 and to $13 \%, 8 \%$ and $12 \%$ in scenarios sMR-DE, aMR-DE and FR-DE 682 respectively. As also reported by Groot et al. (2014), the lightness and 683 bulkiness of plastic makes cost-effective transport challenging. Nevertheless, 684 the ranking of financial results resembles the baseline case: scenario sMR 685 shows a net expenditure (109 EUR/FU in both scenarios sMR-IT and sMRF$686 \mathrm{DE})$, scenario aMR provides consistent savings (-216 EUR/FU in scenario 687 sMR-IT and -316 EUR/FU in scenario sMR-DE), and scenario FR is close to a 688 financial zero (-3EUR/FU in scenario sMR-IT and -6 EUR/FU in scenario 689 sMR-DE). However, if transportation costs are assumed associated to the 690 exporting country (i.e Denmark), then depending on the choice of the recycling 691 scenario the importing country may bear a cost or obtain revenues, while the 692 exporting country may always bear a cost.

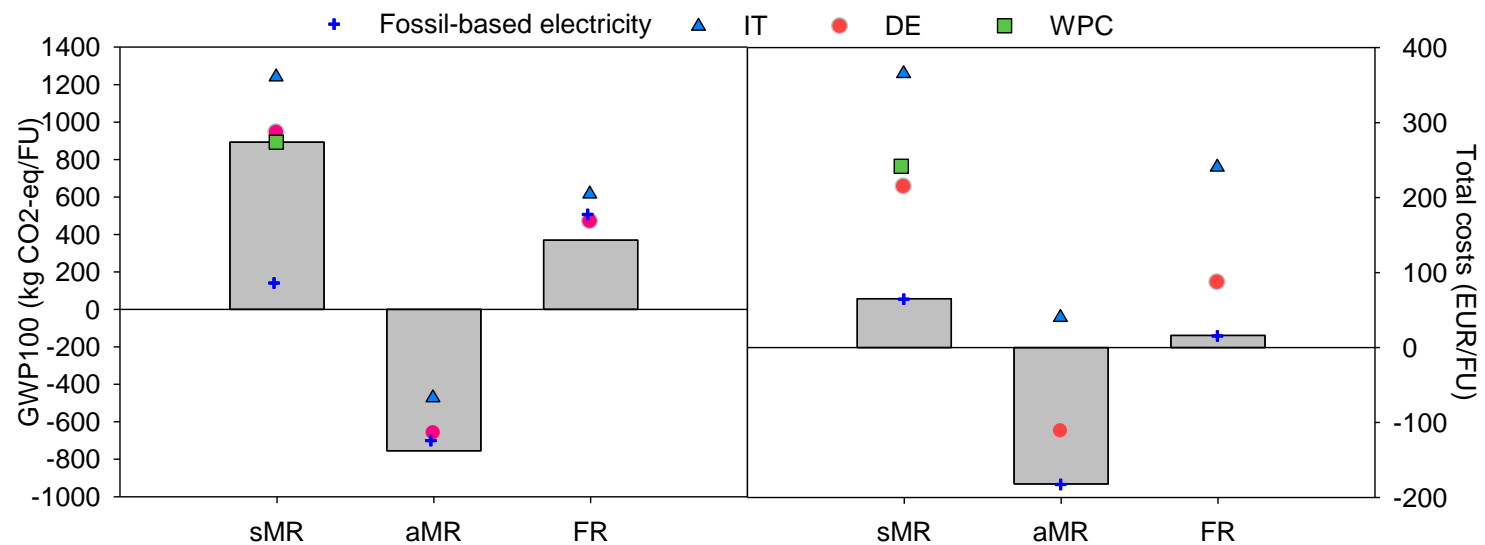

694 Figure 5. Global Warming Potential 100 (left-hand graph) and total costs (right-hand graph) 695 results for scenario analysis on the provision of electricity (red cross symbol), the geographic 696 location of the facility (black triangular symbol and grey circle symbol), and the substitution 697 of WPC (grey square symbol). 
The last system assumption investigated by scenario analysis evaluated the

700 results for scenario sMR in case the recycled pellets were used in wood plastic

701 composites (WPC) rather than recycling into plastic products. The results from

702 the environmental assessment did not change, as the substituted material

703 (virgin plastic pellet) did not change. However, the total costs increased from

$70465 \mathrm{EUR} / \mathrm{FU}$ in the baseline scenario to $229 \mathrm{EUR} / \mathrm{FU}$ in scenario sMR-WPC

$705(+252 \%)$. This increase was caused by the lower prices that recycled pellets

706 reach as raw material for the production of WPC (or other types of composites):

707 the plastic is used as filler and its aesthetics/purity are less important compared

708 with "pure" plastic application. This clearly illustrates that higher overall costs

709 may be associated with recovering and recycling lower-quality plastic.

\section{Conclusions}

711 Drawing upon the comparison of three key arch-types of hard plastic waste 712 recycling routes (two mechanical recycling scenario characterised by a simpler 713 - sMR - and a more advanced - aMR - technology, respectively and one 714 feedstock recycling scenario by pyrolysis - FR) we showed that quality715 oriented recycling is preferable from both an environmental and financial 716 assessment perspective. Scenario aMR provided the largest savings in the 717 highest number of impact categories, including global warming potential 718 (GWP). Scenario sMR typically ranked second, apart from the case of GWP 719 were the pyrolysis alternative appeared more beneficial than a simple material 720 recovery facility (MRF) treatment due to considerable emissions from 721 incinerating a large amount of plastic rejects. Scenario aMR also provided the 722 lowest total costs (negative costs), followed by FR and sMR scenarios (positive 723 costs). The results demonstrated that if high quality of the recycled plastic is 724 achieved, then both environmental savings and financial revenues are possible. 725 Therefore, an advanced MRF treatment should be preferred for management of 726 hard plastic waste from recycling centres. Typically, three to nine model 727 parameters were sufficient to account for more than $90 \%$ of the total variance 728 in the results: increased efforts should be put to model such parameters 729 correctly, as the results will be largely dependent on them. The most important 730 parameters in the highest number of impact categories were related to sorting 731 efficiencies, technical yields and market substitution factors; these parameters 732 should be addressed specifically (i.e. maximised) when increasing the 733 environmental and financial savings is targeted. The ranking of scenarios was 734 found to be robust with respect to assumptions on energy provision, location 735 of recycling facilities and application of the recycled material (addressed by 
736 scenario analysis). The resource quality was identified as a driving force 737 towards economically and environmentally sustainable recycling, indicating 738 that from a circular economy perspective "better recycling" may be preferable 739 over "more recycling".

\section{Acknowledgment}

741 The Danish Environmental Protection Agency is highly appreciated for 742 funding this study. The authors are also grateful to U. Arena (II University of 743 Naples), S.A. Bassi and V. Bisinella (Technical University of Denmark), I. 744 Puig (Fundació ENT) and A. Villanueva (Joint Research Centre) for useful 745 comments on the study.

\section{Funding}

747 This work was supported by the Danish Environmental Protection Agency 748 (Miljøstyrelsen). 


\section{References}

Alston, S.M., Arnold, J.C., 2011. Environmental impact of pyrolysis of mixed WEEE plastics part 2: Life cycle assessment. Environ. Sci. Technol. 45, 9386-9392. https://doi.org/10.1021/es2016654

Alwaeli, M., 2010. The impact of product charges and EU directives on the level of packaging waste recycling in Poland. Resour. Conserv. Recycl. 54, 609-614. https://doi.org/10.1016/j.resconrec.2009.11.011

Al-salem, S.M., Evangelisti, S., Lettieri, P., 2014. Life cycle assessment of alternative technologies for municipal solid waste and plastic solid waste management in the Greater London area. Chem. Eng. J. 244, 391-402. https://doi.org/10.1016/j.cej.2014.01.066

Arena, U., Mastellone, M.L., Perugini, F., 2003. Life Cycle assessment of a plastic packaging recycling system. Int. J. Life Cycle Assess. 8, 92-98. https://doi.org/10.1007/BF02978432

ASTM Standard D5033, 2000. Standard guide to development of ASTM standards relating to recycling and use of recycled plastics. West Conshohocken. ASTM International. https://doi.org/10.1520/D5033-00

Astrup, T.F., Bilitewski, B., 2010. Pyrolysis and Gasification. In Christensen, T. H. (Eds.), Solid Waste Technology \& Management, Chapter 8.8. John Wiley \& Sons, Ltd, Chichester (ISBN: 978-1-405-17517-3).

Axion Consulting. 2014. Plastic to oil products - Final report. Available at: www.zerowastescotland.org.uk

Beigl, P., Salhofer, S., 2004. Comparison of ecological effects and costs of communal waste management systems 41, 83-102. https://doi.org/10.1016/j.resconrec.2003.08.007

Benavides, P.T., Sun, P., Han, J., Dunn, J.B., Wang, M., 2017. Life-cycle analysis of fuels from post-use non-recycled plastics. Fuel 203, 11-22. https://doi.org/10.1016/j.fuel.2017.04.070

Bernardo, C.A., Simões, C.L., Pinto, L.M.C., Bernardo, C.A., Simões, C.L., Pinto, L.M.C., 2016. Environmental and Economic Life Cycle Analysis of Plastic Waste Management Options . A Review 140001. https://doi.org/10.1063/1.4965581

Bisinella, V., Conradsen, K., Christensen, T.H., Astrup, T.F., 2016. A global approach for sparse representation of uncertainty in Life Cycle Assessments of waste management systems. Int. J. Life Cycle Assess. 21, 378-394. https://doi.org/10.1007/s11367-015$1014-4$

Bisinella, V., Astrup, T.F., Højlund, T., 2017. Future scenario development within life cycle assessment of waste management systems. Technical University of Denmark.

Brems, A., Baeyens, J., Dewil, R., 2012. Recycling and recovery of post-consumer plastic solid waste in a European context. Therm. Sci. 16, 669-685. https://doi.org/10.2298/TSCI120111121B 
BS-EN 1542, 2007. Plastics. Recycled plastics. Characterization of polystyrene (PS) recyclates. Published January 2008.

BS-EN 1543, 2007. Plastics. Recycled plastics. Plastics recycling traceability and assessment of conformity and recycled content. Published January 2008.

BS-EN 1544, 2007. Plastics. Recycled plastics. Characterization of polyethylene (PE) recyclates. Published January 2008.

BS-EN 1545, 2007. Plastics. Recycled plastics. Characterization of polypropylene (PP) recyclates. Published February 2008.

BS-EN 1546, 2014. Plastics. Recycled plastics. Characterization of poly(vinyl chloride) (PVC) recyclates. Published November 2014.

BS-EN 1547, 2007. Plastics. Recycled plastics. Characterization of plastics waste. Published January 2008.

BS-EN 1548, 2014. Plastics. Recycled plastics. Characterization of poly(ethylene terephthalate) (PET) recyclates. Published November 2014.

Clavreul, J., Guyonnet, D., Christensen, T.H., 2012. Quantifying uncertainty in LCAmodelling of waste management systems. Waste Manag. 32, 2482-2495. https://doi.org/10.1016/j.wasman.2012.07.008

Clavreul, J., Baumeister, H., Christensen, T.H., Damgaard, A., 2014. An environmental assessment system for environmental technologies. Environ. Model. Softw. 60, 18-30. https://doi.org/10.1016/j.envsoft.2014.06.007

Clean, 2017. Appendix 4 - Preliminary technical specifications. Available at: https://www.cleancluster.dk/documents-and-conditions-the-tender/

Da Cruz, N.F., Simões, P., Marques, R.C., 2012. Economic cost recovery in the recycling of packaging waste: the case of Portugal 37, 8-18. https://doi.org/10.1016/j.jclepro.2012.05.043

DRS (Dansk Retur System), 2015. Årsrapport 2015. Det hele værd (Annual report 2015. It's worth it). Availabel at: http://www.danskretursystem.dk/wpcontent/uploads/2016/05/Aarsrapport_2015_Low.pdf

EC (European Commission), 2008. Directive 2008/98/CE of the European Parliament and of the Council of 19 November 2008 on waste and repealing certain Directives. Official Journal of the European Union.

EC (European Commission). 2016. EU reference scenario 2016. Energy, transport and GHG emissions - Trends to 2050. https://ec.europa.eu/energy/en/content/2013-\%E2\%80\%93eu-energy-transport-and-greenhouse-gas-emissions-trends-2050

EC (European Commission), 2018. Communication from the Commission to the European Parliament, the Council, the European Economic and Social Committee and the Committee of the Regions - A European Strategy for Plastics in a Circular Economy. Commission staff working document. Brussels, $125 \mathrm{pp}$. 
Elli, L., Pagani, R., 2017. Fuel oil from plastic waste plant - Technical description.

Eriksson, O., Finnveden, G., 2009. Plastic waste as a fuel - CO2-neutral or not? Energy Environ. Sci. 2, 907. https://doi.org/10.1039/b908135f

European Environment Agency (EEA), 2016. More from less - material efficiency in Europe. 2015 overview of policies, instruments and targets in 32 Countries. Report No. 10/2016. Available at: https://www.eea.europa.eu/publications/more-from-less

European Parliamentary Research Service (EPRS), 2016. Closing the loop - New circular economy package. Briefing. Available at: http://www.europarl.europa.eu/RegData/etudes/BRIE/2016/573899/EPRS_BRI(2016)57 3899_EN.pdf

Eurostat, 2017a. Electricity price statistics. Available at: http://ec.europa.eu/eurostat/statisticsexplained/index.php/Electricity_price_statistics\#Further_Eurostat_information Last accessed 24.01.2018

Eurostat, 2017b. Natural gas price statistics. Available at: http://ec.europa.eu/eurostat/statistics-

explained/index.php/Electricity_price_statistics\#Further_Eurostat_information Last accessed 24.01.2018

Eurostat, 2017c. Hourly labour cost. Available at: http://ec.europa.eu/eurostat/statistics explained/index.php/Hourly_labour_costs Last accessed 24.01.2018.

Ferreira, S., Cabral, M., Cruz, N.F., Simões, P., Marques, R.C., 2014. Life cycle assessment of a packaging waste recycling system in Portugal. Waste Manag. 34, 1725-1735. https://doi.org/10.1016/j.wasman.2014.05.007

Gear, M., Sadhukhan, J., Thorpe, R., Clift, R., Seville, J., Keast, M., 2018. A life cycle assessment data analysis toolkit for the design of novel processes - A case study for a thermal cracking process for mixed plastic waste. J. Clean. Prod. 180, 735-747. https://doi.org/10.1016/j.jclepro.2018.01.015

Giugliano, M., Cernuschi, S., Grosso, M., Rigamonti, L., 2011. Material and energy recovery in integrated waste management systems. An evaluation based on life cycle assessment. Waste Manag. 31, 2092-2101. https://doi.org/10.1016/j.wasman.2011.02.029

Groen, E.A., Heijungs, R., Bokkers, E.A.M., de Boer, I.J.M., 2014 Methods for uncertainty propagation in life cycle assessment. Environ. Model. Softw. 62, 316-325.

Groot, J., Bing, X., Bos-brouwers, H., Bloemhof-ruwaard, J., 2014. A comprehensive waste collection cost model applied to post-consumer plastic packaging waste. Resour. Conserv. Recycl. 85, 79-87. https://doi.org/10.1016/j.resconrec.2013.10.019

Gu, F., Guo, J., Zhang, W., Summers, P.A., Hall, P., 2017. From waste plastics to industrial raw materials: A life cycle assessment of mechanical plastic recycling practice based on a real-world case study. Sci. Total Environ. 602, 1192-1207. https://doi.org/10.1016/j.scitotenv.2017.05.278 
Hage, O., Söderholm, P., 2008. An econometric analysis of regional differences in household waste collection: The case of plastic packaging waste in Sweden 28, 1720-1731. https://doi.org/10.1016/j.wasman.2007.08.022

Hauschild, M.Z., Goedkoop, M., Guinée, J., Heijungs, R., Huijbregts, M., Jolliet, O., Margni, M., De Schryver, A., Humbert, S., Laurent, A., Sala, S., Pant, R., 2013. Identifying best existing practice for characterization modeling in life cycle impact assessment. Int. J. Life Cycle Assess. 18, 683-697. https://doi.org/10.1007/s11367-0120489-5

Hunkeler, D., Lichtenvort, K., Rebitzer, G., 2008. Environmental Life Cycle Costing. Webster, New York, USA.

Ignatyev, I.A., Thielemans, W., Vander Beke, B., 2014. Recycling of polymers: A review. Chem. Sus. Chem. 7, 1579-1593. https://doi.org/10.1002/cssc.201300898

Institute of Scrap Recycling Industry (ISRI), 2017. Scrap specifications circular. Guidelines for non ferrous scrap, ferrous scrap, glass cullet, paper stock, plastic scrap, electronics scrap, tire scraps. Available at: http://www.scrap2.org/specs/files/assets/basic-html/pageI.html\#

International Energy Agency (IEA), 2017. Energy Policies of IEA Countries - Denmark 2017 Review.

https://www.iea.org/publications/freepublications/publication/EnergyPoliciesofIEACou ntriesDenmark2017Review.pdf

ISO 14040, 2006. Environmental Management-Life Cycle Assessment-Principles and Framework, second ed. ISO, Geneva, Switzerland.

Krook, J., Eklund, M., 2010. The strategic role of recycling centres for environmental performance of waste management systems. Appl. Ergon. 41, 362-367. https://doi.org/10.1016/j.apergo.2009.06.012

Larsen, A.W., Merrild, H., Møller, J., Christensen, T.H., 2010. Waste collection systems for recyclables : An environmental and economic assessment for the municipality of Aarhus (Denmark). Waste Manag. 30, 744-754. https://doi.org/10.1016/j.wasman.2009.10.021

Lazarevic, D., Aoustin, E., Buclet, N., Brandt, N., 2010. Plastic waste management in the context of a European recycling society: Comparing results and uncertainties in a life cycle perspective. Resour. Conserv. Recycl. 55, 246-259. https://doi.org/10.1016/j.resconrec.2010.09.014

Laurent, A., Clavreul, J., Bernstad, A., Bakas, I., Niero, M., Gentil, E., Christensen, T.H., Hauschild, M.Z., 2014. Review of LCA studies of solid waste management systems - Part II: Methodological guidance for a better practice. Waste Manag. 34, 589-606. https://doi.org/10.1016/j.wasman.2013.12.004

Lea, W.R., 1996. Plastic incineration versus recycling : a comparison of energy and la ndfill cost savings. J. Hazard. Mater. 47, 295-302. 
Lofti, A., 2003. Plastic recycling. Available at: http://www.lotfi.net/recycle/plastic.html (Accessed December 2017)

Martinez-Sanchez, V., Kromann, M.A., Astrup, T.F., 2015. Life cycle costing of waste management systems: Overview, calculation principles and case studies. Waste Manag. 36, 343-355. https://doi.org/10.1016/j.wasman.2014.10.033

Martinez-Sanchez, V., Hulgaard, T., Hindsgaul, C., Riber, C., Kamuk, B., Astrup, T.F., 2016. Estimation of marginal costs at existing waste treatment facilities. Waste Manag. 50, 364-375. https://doi.org/10.1016/j.wasman.2016.02.032

Massarutto, A., Carli, A. de, Graffi, M., 2011. Material and energy recovery in integrated waste management systems: A life-cycle costing approach. Waste Manag. 31, 21022111. https://doi.org/10.1016/j.wasman.2011.05.017

Miljøstyrelsen, 2014. Faktaark - Dit og Danmarks affald (Facts about recycling). Available at: http://mst.dk/affald-jord/affald/affaldshaandtering-strategi-aktiviteter/faktaark-omdanmark-uden-affald/ (In Danish).

Miljøstyrelsen, 2015. Mekanisk sortering af plastaffald fra husholdninger - Udvikling af dansk sorteringskoncept. (Mechanical sorting of plastic waste from households Development of Danish sorting concept). Environmental project No. 1724. Available at: https://www2.mst.dk/Udgiv/publikationer/2015/06/978-87-93352-37-7.pdf (In Danish).

Miljøstyrelsen, 2017a. Waste Statistics 2015. Environmental Project no. 1955. Copenhagen, 60 pp. Available at: http://www.mst.dk

Miljøstyrelsen, 2017b. Genbrugsplast: Fra husholdningsaffald til husholdningssorteringssystem. (Recycling plastic: From household waste to household sorting system). Environmental Project No. 1951. Copenhagen, 114pp. In Danish.

Muñoz, I. (2015). Example - Marginal Electricity in Denmark. Version: 2015-12-10. www.consequential-lca.org

Overgaard, K.Z., Mosgaard, M., Riisgaard, H., 2018. Capturing uncaptured values - A Danish case study on municipal preparation for reuse and recycling of waste. Resour. Conserv. Recycl. 136, 297-305. https://doi.org/10.1016/j.resconrec.2018.04.031

Perugini, F., Mastellone, M.L., Arena, U., 2005. A life cycle assessment of mechanical and feedstock recycling options for management of plastic packaging wastes. Environ. Prog. 24, 137-154. https://doi.org/10.1002/ep.10078

Plastic Europe, 2016. Plastics - the facts 2016. An analysis of European plastics production, demand and waste data Available http://www.plasticseurope.org/documents/document/20161014113313plastics_the_facts_2016_final_version.pdf.

Ragaert, K., Delva, L., Van Geem, K., 2017. Mechanical and chemical recycling of solid plastic waste. Waste Manag. 69, 24-58. https://doi.org/10.1016/j.wasman.2017.07.044 
RDC Environment \& Pira International, 2003. Evaluation of costs and benefits for the achievement of reuse and recycling targets for the different packaging materials in the frame of the packaging and packaging waste directive - Final Consolidated Report.

Rigamonti, L., Falbo, A., Grosso, M., 2013. Improving integrated waste management at the regional level: The case of Lombardia. Waste Manag. Res. 31, 946-953. https://doi.org/10.1177/0734242X13493957

Rigamonti, L., Grosso, M., Møller, J., Sanchez, V.M., Magnani, S., Christensen, T.H., 2014. Environmental evaluation of plastic waste management scenarios. Resour. Conserv. Recycl. 85, 42-53. https://doi.org/10.1016/j.resconrec.2013.12.012

Rigamonti, L., Ferreira, S., Grosso, M., Marques, R.C., 2015. Economic-financial analysis of the Italian packaging waste management system from a local authority's perspective. J. Clean. Prod. 87, 533-541. https://doi.org/10.1016/j.jclepro.2014.10.069

Sadhukhan, J., Ng, K.S., Martinez-Hernandez, E., 2016. Novel integrated mechanical biological chemical treatment (MBCT) systems for the production of levulinic acid from fraction of municipal solid waste: A comprehensive techno-economic analysis. Bioresour. Technol. 215, 131-143. https://doi.org/10.1016/j.biortech.2016.04.030

Sadhukhan, J., Martinez-Hernandez, E., 2017. Material flow and sustainability analyses of biorefining of municipal solid waste. Bioresour. Technol. 243, 135-146. https://doi.org/10.1016/j.biortech.2017.06.078

Shonfield, P., 2008. LCA of Management Options for Mixed Waste Plastics, Waste resource action programme WRAP. London. https://doi.org/1-81105-397-0

Sommerhuber, P.F., Wang, T., Krause, A., 2016. Wood-plastic composites as potential applications of recycled plastics of electronic waste and recycled particleboard. J. Clean. Prod. 121, 176-185. https://doi.org/10.1016/j.jclepro.2016.02.036

Swarr, T.E., Hunkeler, D., Klöpffer, W., Pesonen, H., Ciroth, A., Brent, A.C., Pagan, R., 2011. Environmental life-cycle costing: a code of practice. Int. J. Life Cycle Assess. 389-391. https://doi.org/10.1007/s11367-011-0287-5

Sweco Danmark A/S. 2015. Plastkortlægning (Plastic mapping). Report. Copenhagen, December 7. In Danish.

Turconi, R., Butera, S., Boldrin, a., Grosso, M., Rigamonti, L., Astrup, T., 2011. Life cycle assessment of waste incineration in Denmark and Italy using two LCA models. Waste Manag. Res. 29, S78-S90. https://doi.org/10.1177/0734242X11417489

Vandenbo, C., Hellweg S., Astrup T., 2017. Let's Be Clear(er) about Substitution: A Reporting Framework to Account for Product Displacement in Life Cycle Assessment. J. Ind. Ecol., 21(5), 1078-1089

Valentino, G., Niero, M., Rigamonti, L., 2016. Life Cycle Assessment of PET bottles: closed and open loop recycling in Denmark and Lombardy region. MSc thesis. 162 pp.

Vazquez, Y.V., Barbosa, S.E., 2016. Recycling ofmixed plasticwaste fromelectrical and electronic equipment. Added value by compatibilization. WasteManag. 53, 196-203. 
Villanueva, A., Eder, P., 2014. End-of-Waste Criteria for waste plastic for conversion, JRC Technical Reports. Luxemburg. https://doi.org/10.2791/13033

Yu, J., Sun, L., Ma, C., Qiao, Y., Yao, H., 2016. Thermal degradation of PVC: A review. Waste Manag. 48, 300-314. https://doi.org/10.1016/j.wasman.2015.11.041

Weidema, B., Ekvall, T., Heijungs, R., 2009. Guidelines for application of deepened and broadened LCA.

Wrap, 2009. A financial assessment of recycling mixed plastics in the UK. 